\title{
Applied Ethnobotany: People, Medicinal Plants Use and Conservation Practices in Benishangul Gumuz Regional State of Ethiopia: The future cursed natural resource in the Region
}

\section{Research Article}

Volume 1 Issue 1- 2021

\begin{abstract}
Author Details
Dereje Mosissa ${ }^{1 \star}$ and Hailu Atinafu ${ }^{2}$

${ }^{1}$ Ethiopian Biodiversity Institute Assosa Biodiversity Center, Forest and Rangland Biodiversity Caseteam, Ethiopia

${ }^{2}$ Ethiopian Biodiversity Institute Forest and Rangland Biodiversity Directorate, Ethiopia

*Corresponding author

Dereje Mosissa, Ethiopian Biodiversity Institute Assosa Biodiversity Center, Forest and Rangland Biodiversity Caseteam, Ethiopia
\end{abstract}

\section{Article History}

Received: March 22, 2021 Accepted: April 15, 2021 Published: April 20, 2021

\begin{abstract}
An ethnobotanical study of medicinal plants used by the communities in Wombera District, Benishangual Gumuz Regional State, Western Ethiopia was carried out from 0ctober, 2019 to October, 2020. The purpose of the study was to document information of medicinal plants and indigenous knowledge on use and conservation of medicinal plants by the communities of Wombera District. A purposive sampling was designed and employed for selection of the study areas ( 6 sampling sites) and 200 informants (52 males and 18 females) aged between 18-85 years were randomly selected from 6 kebeles. Ethnobotanical data were collected using semi-structured questionnaires, interview and, group discussion s. A total of 91 medicinal plants were documented from the study area. Of these 60 were human, 7 veterinary and 24 both human and veterinary medicines. Data were analyzed quantitatively. The highest number of medicinal plants was collected from wild habitat (64\%), while $33 \%$ was collected from home garden, $3 \%$ occurred both in wild habitat and home garden. The most plant parts used in treatment of human disease were leaves (34.6\%) followed by roots (20.9\%). The most frequently mentioned mode of administration was oral (54\%) followed by dermal $(27.5 \%)$ and the least was found to be application through eyes and ears (3\%) each. The most common form of medicine preparation was crushing, pounding and homogenizing in water (43.07\%) followed by boiling and Fumigating (16\%), squeezing (15.45\%), chewing (10.7) and the least were burning and cooking (5\%) each. Deforestation for agriculture, over exploitation, firewood collection, and overgrazing were the main threats of medicinal plants in the study area. The biggest problem of traditional medicinal remedies is the accurate dosage, which sometimes may even kill. Moreover lack of awareness of cultivation in home garden resulted as threats of medicinal patient.
\end{abstract}

Keywords: Deforestation; Ethnobotany; Indigenous knowledge; Traditional medicine; Wombera district

\section{Introduction}

In all parts of the world, traditional medicinal plant practices formed the basis of health cares for both human beings and animals before the advent of modern medicine. In Ethiopia, people have been using traditional medicine to treat both human and animal diseases for generations. Traditional medicine is still wildly practices in the rural area where modern medicine and services available [1]. Traditional medicinal plants are also used for various purposes in addition to their medicinal values such as forage, firewood, spics, construction, food, cosmetics, clothes, a shelter for human habitats for wild animals and insects. Furthermore, medicinal plants play a significant role in maintaining ecosystem stability, export accommodation and as a fumigant [2].

Traditional herbal remedies can also be used as scientific resources to develop a new drug which is safes. It is also effectively the cheapest and environmental sounds. Many of today's wonderful drugs were initially discovered through the study of traditional medicine [1]. There is a large number of moderate to the high value of medicinal plants herbs 
and species existing in the world. However, of the existing medicinal herbs species only a small percent are treaded $[2,3]$.

Availability of medicinal plants has been affected by a dramatic decrease of native vegetation due to agricultural explanation, deforestation, fire, and overgrazing drought, the tread of charcoal, firewood, the introduction of alien invasive species and urban associated development. Globally the estimates of medicinal plant species range from $35,000-50,000$ and out of this about 4, 000-6,000 species have entered the world market of medicinal plants [4]. Many Ethiopian medicinal plants have undergone scientific investigation. Ethiopia has a high diversity of plants and animals due to its varieties of climate and topography. The use of medicinal plants for primary healthcare needed has been practiced by the local population across the world for centuries and still existing in their lifestyle at present.

The cultural indigenous knowledge of medicinal plants in Ethiopia in unevenly distributed among each community numbers. People in a different location with different religions and cultural background have their specific knowledge about the use of plants which in the part has generally entered wide circulation in the country. The knowledge about the use of plants is largely oral, however, Ethiopians ancient church practices have documented some knowledge as inscribed as medico religious written in geez manuscripts of $16^{\text {th }}$ [5]. Medicinal plants obtained from wild habitats are found in different natural ecosystems of the forests, grasslands, woodlands, wetlands, in field margins and garden fences, as weeds and in many other microhabitats from where they are harvested when the need arise (Endashew Bekele, 2016).

Plantations of medicinal plants can be made in degraded and degrading areas. Many medicinal plants of Ethiopia have good properties for land rehabilitation and erosion control which could be planted in different agroecological settings. In-situ and ex-situ conservation strategies work well when they complement one another since what is not achievable by one method is backed by the other method. In addition to this scheme that would enable sustainable use of medicinal plants and the associated indigenous knowledge should be developed with the best practice of benefit -sharing [6].

Maintain health through traditional medicine in general and utilization of medicinal plants, in particular, is almost as old as the history of man kinds. This is true in Ethiopia $80 \%$ of the population still relies on the plant to prevent and cure various health problem [2]. The current plant use trend in the Wombera district shows that the environment is facing problems of resource depletion and loss of indigenous knowledge like other areas of the country.

Thus, intensive ethnobotanical research plays a vital role to draw information on plants and related indigenous knowledge for conservation and sustainable utilization. Like many other parts of the country, there is no such ethnomedicinal research and documentation carried out in Wombera District, Metekele Zone, and Northwest. This study, therefore, aimed at documenting indigenous knowledge on the use and management of medicinal plants used to treat human and livestock ailments as well as assessing the existing threats to these medicinal plants in Wombera district.

The loss of medicinal plant taxa is a common problem in Ethiopia for sustainable use [6]. In addition to this, rapid economic growth and cultural changes threaten the traditional lifestyle of indigenous people. As a result, there is a greater danger for the loss of many useful medicinal plants together with traditional knowledge. In developing countries like Ethiopia; the indigenous knowledge about the traditional medicinal plant is transferred secretly from generation to generation orally. Moreover, there is a gap in the documentation and recording of medicinal plants in the country. Medicinal plants in most parts of the country, the wild plants and forests are almost degraded by a human impact like deforestation, agricultural expansion and overexploitation, and population growth and hence there is evident loss of biodiversity.

One part of Ethiopia to see such problems is general Benshangule Gumze Regional State particular in Wombera district. This region is suffering habitat and species loss due to continued deforestation, fire and over usage of medicinal plants as well as a loss of associated knowledge and little has been done to document ethnobotanical knowledge which is basic for conservation and community developments activity. Until this moment, no research on the ethnobotanical study of medicinal plants was conducted in the Wombera district. Hence, this study was initiated and fills gaps of the documentation of ethnobotanical knowledge in the study area.

\section{Material and Methods}

The Benishangul Gumuz Regional State (BGRS) was established in 1994 as one of the nine regional states of Ethiopia. The BGRS borders the Republic of Sudan in the west, Amhara region in the North, and Oromiya in the south and Southeast. Administratively, it is divided into 3 Zones (Metekele, Assosa, and Kemashi) that are divided into 19 districts and one special district. Metekel Zone is divided into 7 Woreda out of which Wombera district is one of the study areas which

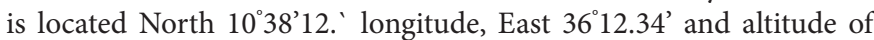
2065masl (Source BGRS, 2008) (Figure 1).

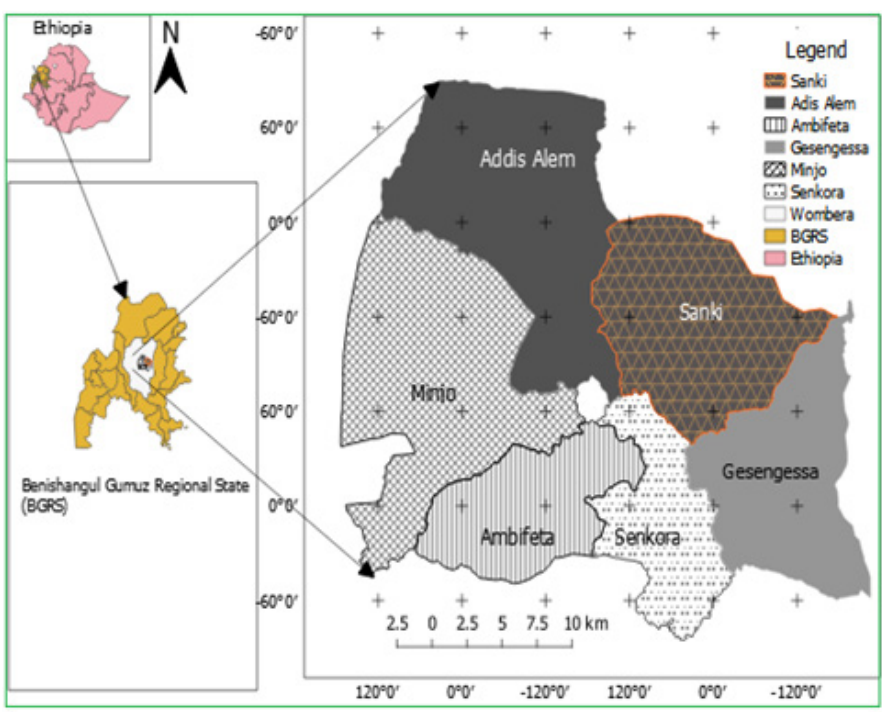

Figure 1: Map of the Study Area Wombera District (Source: own sketch).

This Woreda is part of the Western areas of Ethiopia. The high mountan of the district includes the Gesengesa Mountains in the South-Ester part, which runs along the Shar River into Abay River as it turns to the South. The area comprises a variety of land features, dominantly of plain lowlands (52\%), mountains (31\%) and rugged (14\%) and altitude ranging from 800 to $2165 \mathrm{~m}$.a.s.l. There are three agroecologies: highland (1700-2500m.a.s.l), midland (1500-1700m.a.s.l) and lowland (900-1500m.a.s.l). About $1 \%$ of the woreda is highland, $19 \%$ of the Woreda is midland, and $80 \%$ lowland agroecology. The major soil coverage of the district (65\% is vertisoil, $30 \%$ loamy soils and 5\% sandy soil (WWOA, 2012).

Based on the central statistics data (2007), the total population for the woreda of 66,654 33,452 were men and 33,202 were women; 7,399 or $11.1 \%$ of its population were urban dwellers of all 12,446 were children's.

The total area of the district is estimated to be about 338,289 hectares (111 square kilometres), of which farm land accounts $23 \%$, Forest land $46 \%$, grazing land $13 \%$, cultivable farm land $14 \%$, unusable land $3 \%$ and settlement $1 \%$. The forest land of the Woreda is characterized by 
patchy distribution of different trees that forms dense canopy covers. The Woreda is sub-divided into 34 administrative kebeles, four of them found in town while the rest are rural kebeles

The vegetation of the study district is predominantly composed of different woody and herbaceous species. The natural vegetation of the district is mainly composed of various lowland, highland and midland species such as Ficus spp. (Such as Ficus thonnigi, Ficus sur, Ficus vasta, Ficus mochsttery, and e.t.c.), Cordia africana, Coroton macrostachyus, Adonsonia dgitata, and Dombey torrida. Rosa abyssinica, Hygenea abissinica, Olea europa, Ekbergia capensis, Careissa, and other trees, shrub and herbaceous species (WWOA, 2012).

Agroecologically, Wombera District is classified as high temperature area $(75 \%)$, medium temperature area (15\%) and low temperature area $(10 \%)$. Based on 5 years climatic data obtained from National Meteorological Service Agency (NMSA), the average annual rainfall is $186.6 \mathrm{~mm}$ and the average annual temperature is 21.5 . The annual mean minimum and maximum temperature are 10.025 and 23.8 respectively. The total mean annual rain fall is ranges from 900 $1400 \mathrm{~mm}$ and the highest rain fall was recorded in August (Figure 2).

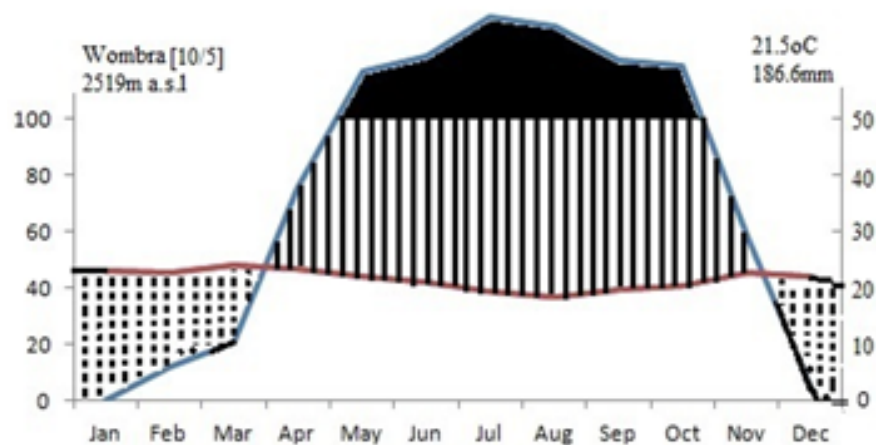

Figure 2: Climadiagram of Wombera District as following the method of Walter (1985) (Source: own sketch).

(Data Source: obtained from National Meteorological Service Agency, Bahir Dar Branch).

In terms of economic activity, agriculture is the dominant economic sector in the district from which nearly $92.5 \%$ of the total population derives its livelihood. The major source of income in the Woreda specially for highlanders are coffee farming. Crop production with animal rearing is also a side line economic activity for much of the farming community. In addition to that few shinasha community members are engaged in selling medicinal plants for other community members to support their income. (Sources WWAO, 2008).

\section{Methodology}

\section{Reconnaissance survey and selection of study sites}

Reconnaissance survey was conducted from November 1 to 30, 2019, in the study Wereda to obtain an impression about medicinal plants, topography, distribution of plants, and identification of sampling sites. During the survey 5 representative Kebeles were selected purposively for ethnobotanical data collection based on the availability of traditional medicinal practitioners, the availability of larger vegetation cover present, and the availability of high shinasha peoples who were known to practice traditional medicine. Local administrators were chosen as key resource persons in providing information in their respective Kebeles. During the survey, general information about the Woreda was also be obtained.

\section{Informant selection}

Information regarding to each farmer association of the people in the study area was based on simple random sampling strategy. The sample size was determined by using the formula of [7].

\section{$\mathrm{n}=\frac{N}{1+N(e)^{2}}$}

Where $\mathrm{n}$ is sample size of the study area

$\mathbf{N}$ is targeted population size (total population of five kebele in study area.)

e: is the level of precision or sampling error $=(0.05)$

For the above formula.

From the five studies kebele twenty key informants were purposively selected based on recommendations from local authorities (kebele administrators and local guiders) farmer association leaders and other members of the local communities. The traditional healer, used as key informants, were identified by with the assistance of local authorities, elders and knowledgeable persons.

\section{Specimen collection and identification}

At the end of the interview, the reported medicinal plants were collected from natural vegetation and home gardens. Voucher sample specimens of the plants cited for their medicinal use were collected, numbered, pressed and dried for identification. Voucher identification was performed both in the field, and at office, using the Flora of Ethiopia and Eritrea and also by comparison with authenticated figures.

\section{Ethnobotanical data collection}

Ethnobotanical data was collected between Octobers 2019 to June 2020 on three field trips. The data were collected based on prepared questionnaires, semi-structured interviewees, observation, focus group discussion, and guided field walks with informants to obtain indigenous knowledge of the local communities. The informants that were collected included the various data sets such as local names, disease treated, parts of the plant used, and method of preparation, dosage and route of application. A list of question was prepared that covers the discussion with the informants in particular orders. All of the interviews ware held in Amharic and some were translated in to Shinashigna and Oromigna languages of the local people. The place and time for discussion was set based on the interest of the informants [8].

\section{Semi-structured interview}

Semi-structured interviews were conducted in places where the informants were most comfortable and during the time they have wanted or chosen. During the interview information regarding local name of medicinal plant, parts used, methods of preparation, mode of application, ingredients used in combination, threats and management and other relevant information were recorded from key informants, elders and other knowledgeable informants.

\section{Group discussion}

The discussion was made with volunteer traditional healers and knowledgeable farmers about the knowledge and use of important medicinal plants. At the time of discussion, all informants were allowed to talk freely without interruption. All relevant information such as plant species used to treat different diseases, local names; parts of plants used, ailments treated, method of preparation, and degree of management and details of medicine administration were discussed.

\section{Guided field walk and observation}

A guided field walk was performed with informants as they were interviewed during the trip. Based on ethnobotanical information provided by informants, voucher specimens were collected during guided field walk, numbered, named, pressed, dried and identified.

Interviews and discussions were based on a checklist of topics or questions prepared beforehand in English and translated to Amharic, 
shinashigna and Oromigna languages. Most of the interviews and discussions were held in Amharic by using a translator and information was gathered technically by the researcher from the villagers.

\section{Data Analysis}

\section{i) Ethnobotanical data analysis}

The Ethnobotanical data collected will be analyzed following survey and analytical tools for ethnobotanical methods which include Informant's preference ranking, descriptive statistic (SPSS, vr 21).

\section{ii) Descriptive statistics}

Descriptive statistical methods such as percentage and frequency was employed to analyze and summarize the data on medicinal plants, associated knowledge, management methods, use, and conservation. The most useful information gathered on medicinal plants reported by local people includes medicinal value, application, methods of preparation, route of application, disease treated, dosage, part and habit used will be analyzed through descriptive statistical analysis according to [8-10].

\section{Results and Discussion}

\section{Socio demographic characteristics of respondents}

Six age groups of respondents were identified: between 20 and 30, between 31 and 40, between 41 and 50, between 51 and 60, between 61 and 70 and then greater or equal to 71 years old. The distribution of informants with respect to age class shows that, the majority of the respondants were in the age class of 41 to 50 (31\%) followed by 51 to $60(25 \%)$ age class. Moreover, the age and sex distribution showed that majority of both sex's (112 out of 200) fall in the middle of the age class (41-60) (Figure 3). The study was indicated that the majority of the traditional healers were elder groups (31\%). From the total informants interviewed, $92 \%$ were married, $5.5 \%$ were single and $2.5 \%$ were divorced. Regarding sex, about 145 (72.5\%) of the major informants were males whereas the remaining $55(27.5 \%)$ were reported as females. Moreover, from the total informants interviewed, $92.50 \%$ were farmer followed by marchant $(4 \%)$ and civil servant $(2.5 \%)$. Regarding educational status of the house holds about 46 (46.46\%) of the respondents interviewed were illiterates followed by grade 1-4 there which is $16 \%$. Grade $5-8$ acounted to $14 \%$ and the remaining $13 \%$ were the respondents which can read and write and very few of the above twelve grade (Table 1).

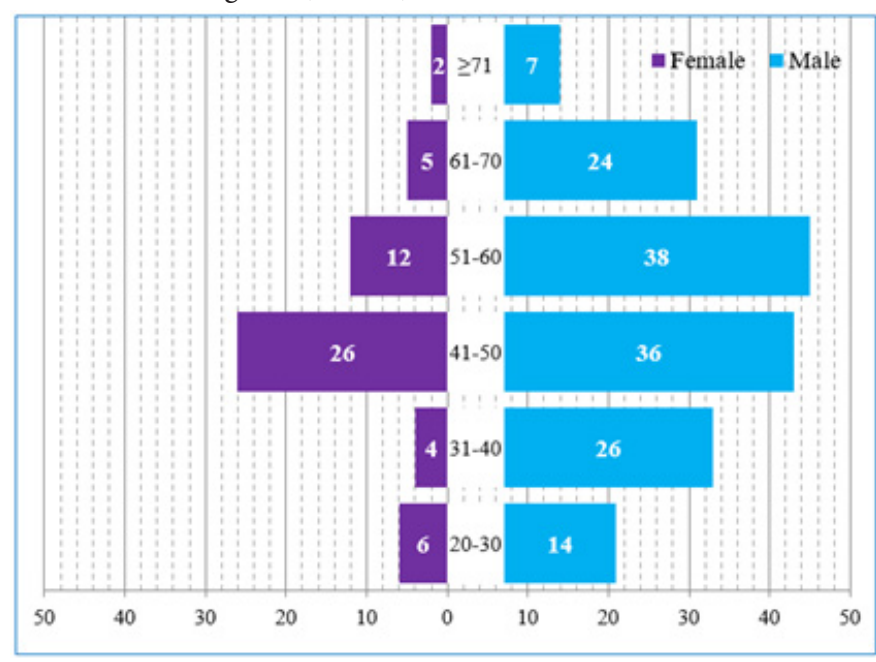

Figure 3: Age and Sex distribution of respondents in the study area (Source: own sketch).

\section{Taxonomy of medicinal plants in Wombera District}

In the study area a total of 91 medicinal plant species that are used for the treatment of human and livestock ailments were gathered and documented. From these, 48(73.8\%) species were used as human medicine, 1 species only (1.54\%) as livestock medicine and the remaining 16 species $(24.62 \%)$ were used for treating both human and livestock ailments (Figure 4). Of these 91 medicinal plants studied, 68 species were gathered from the wild and 17 species from homegardne and the remaining 15 species were available both from wild and home gardens. This result indicates that the local communities mostly depend more on medicinal plants collected from the wild than those from home garden.

Table 1: Characteristics of respondents in the study area $(\mathrm{N}=200)$.

\begin{tabular}{|c|c|c|c|c|}
\hline $\begin{array}{l}\text { HH characteristics } \\
\text { (Variable) }\end{array}$ & \multicolumn{3}{|c|}{ Parameter and Frequency } & Percent \\
\hline \multirow{2}{*}{ Marital Status } & \multicolumn{3}{|c|}{ Sex } & \multirow{2}{*}{ Percentage } \\
\hline & M & F & Total & \\
\hline Single & 6 & 5 & 11 & 5.5 \\
\hline Marred & 138 & 46 & 184 & 92 \\
\hline Divorced & 1 & 4 & 5 & 2.5 \\
\hline Total & 145 & 55 & 200 & $100 \%$ \\
\hline \multirow{2}{*}{ Occupational Status } & \multicolumn{2}{|c|}{ Sex } & & \multirow{2}{*}{ Percentage } \\
\hline & M & $\mathbf{F}$ & Total & \\
\hline Farmer & 134 & 51 & 185 & 92.5 \\
\hline Merchant & 5 & 3 & 8 & 4 \\
\hline Civil servant & 6 & 1 & 7 & 3.5 \\
\hline Total & 145 & 55 & 200 & $100 \%$ \\
\hline \multirow{2}{*}{ Educational Status } & \multicolumn{3}{|c|}{ Informant sex } & \multirow{2}{*}{ Percentage } \\
\hline & $\mathbf{M}$ & F & Total & \\
\hline Illiterate & 60 & 32 & 92 & 46 \\
\hline Read \& Write & 16 & 10 & 26 & 13 \\
\hline 01-Apr & 30 & 2 & 32 & 16 \\
\hline 05-Aug & 22 & 6 & 28 & 14 \\
\hline 09-Dec & 11 & 4 & 15 & 7.5 \\
\hline Above 12 & 6 & 1 & 7 & 3.5 \\
\hline Total & 145 & 55 & 200 & $100 \%$ \\
\hline
\end{tabular}

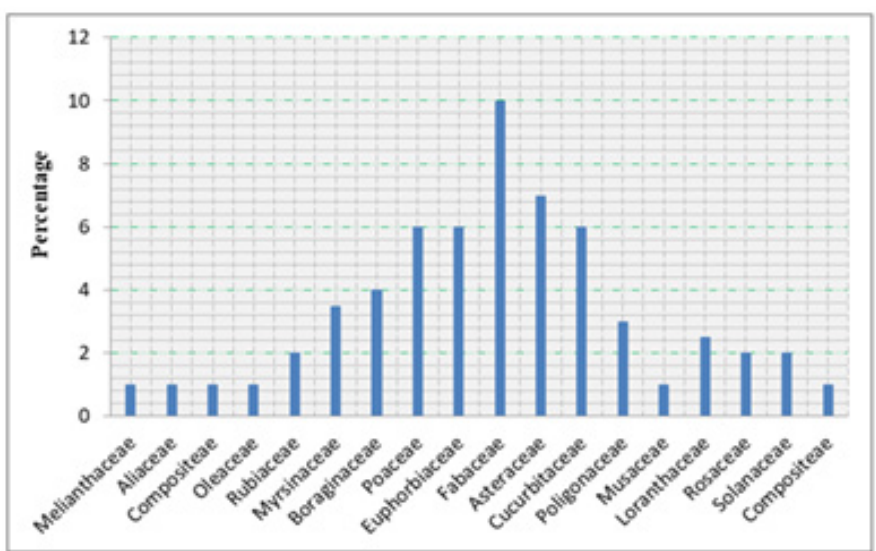

Figure 4: Proportion of families used to treat human ailment (Source: own sketch).

The family distribution indicated that, Fabaceae stood first dominant 7(10.76\%) followed by Asteraceae, Euphorbiaceae and Cucuribitaceae each with four $(6.13 \%)$ species and Combretaceae with three species and other families consist of two representative species in each (Figure 2). Similarly studies of [11-20] confirmed that the abundance of medicinal plant species in Fabaceae family. 


\section{Habit of medicinal plant used in the study area}

\section{Habit of medicinal plants collected from wild}

Medicinal plants collected from wild were clustered into four main different groups based on their habit: tree, shrub, herb, liana or climber/creeper (Figure 5). The clustering indicated that the 23 species in the first main group were trees. Within habit analysis of plant used by the people of Wombera District for treatment of both livestock and human ailments revels that herbs and shrubs take over the second and the third proportion of growth form (Figure 5, 6). However, very few species were under fourth and fifth group.

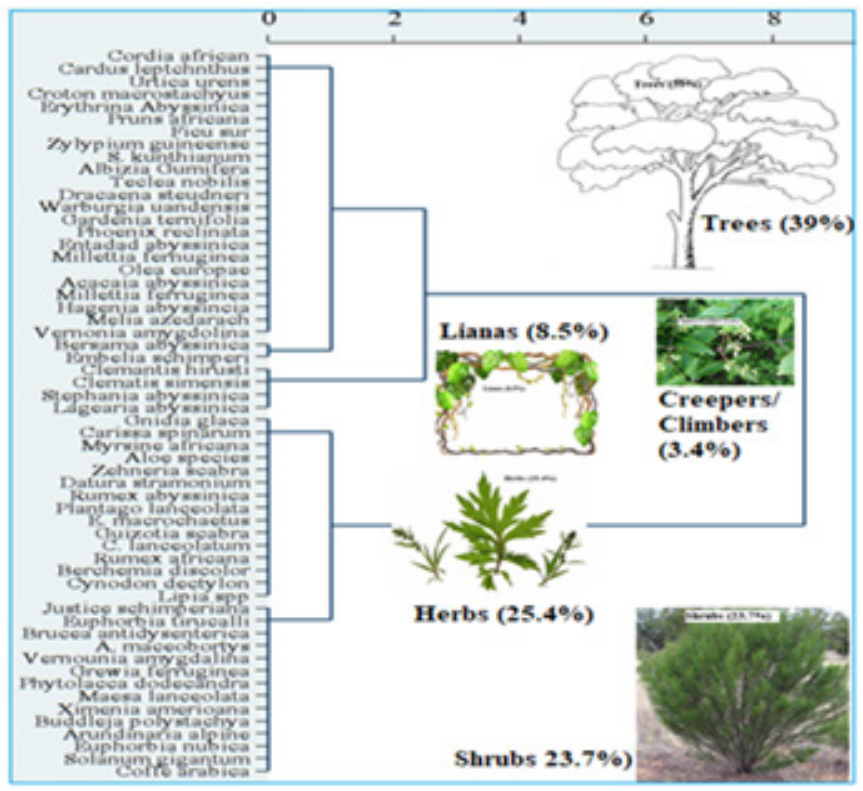

Figure 5: Growth form of medicinal plants used to treat human and livestock ailments (Source: own sketch).

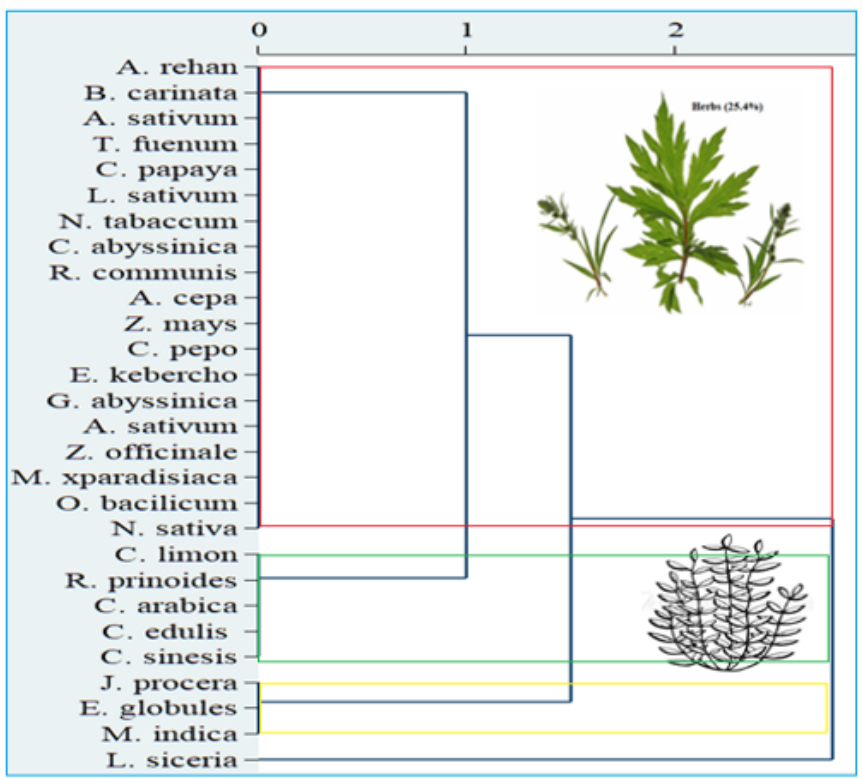

Figure 6: Dendrogram showing the classification of medicinal plant species collected from homegarden based on their habit. The horizontal axis represents the distance or dissimilarity between clusters and the vertical axis represents the species and clusters. Red line is herb; green line is shrub and yellow line is tree. (Source: own sketch).

\section{Habit of medicinal plants collected from homegarden}

As it was indicated below out of 28 medicinal plants documented from home garden, about $66.7 \%$ of plants species were found to be clustered as herbs. Whereas the remaining were grouped as shrubs $(18.5 \%)$ and trees $(11.1 \%)$ (Figure 5).
As it was indicated above out of the total 91 medicinal plants documented, 33 medicinal plants used by the local communities in wombera district were found to be herbs; twenty six of the were trees; nineteen were shrubs and the remaining were cimbers and lianas which is similar to the research done by Mohammed Adefa [21] where as tree is the second dominant medicinal plants in the study area which is $26(28.57 \%)$ followed shrub, climber, epiphytes and lianas respectively .Similar habit distribution of medicinal plants has also been reported by some researchers previously [16-18,22-30].

\section{Habitats and abundance of medicinal plants in the study area}

In this study area medicinal plants were collected from various habitats including wild and home garden. As the result shows that most of the medicinal plants used by the communities were collected from wild 68(73.86\%) and home garden $17(26.15 \%)$.This finding is in line with the general patterns seen in most medicinal plants inventory researchers $([13,14,17,28,31-38]$.

In a similar way, people in the study area have less effort to cultivate medicinal plants in their home gardens rather go to the nearby or far places and harvest the plants. The local people cultivate some popular medicinal plants in their home garden for the purpose of medicine such as Allium sativum, Ocimum lamiifolium, Rhamnus prinoides and Nicotiana tabacum.

This and field observation during data collection clearly confirmed that some traditional healers do not have interest to grow some medicinal plant species in their home garden order to keep them secret and by assuming they may loose their healing power. This means that most of the medicinal plants found in the home gardens are those also known to have other uses particularly as food. This study result also cocures with the study of Dereje Mosissa, et al. [19] which states that in Berta ethnic groups (communities) beliefs in the metaphysical danger destroys the healing powers of medicinal plants have repercussions in respect to the acceptance of domesticated medicinal plants.

\section{Medicinal Plants used to treat human ailments}

Medicinal plants are the primary remedies for treatment of several ailments in the study area. Out of a total 91 medicinal plant collected from the study area 83 plants species $(91.2 \%)$ have great medicinal importance for treatment of human diseases. But it is only 72 plants species $(79 \%)$ which are employed exclusively for treatment of human ailments (Table 2). The taxa distribution of species shows that the plant comprises 63 genera and 44 families.

Accordingly, Fabaceae (Leguminosae) make up the highest proportion, 6 species each $(8.3 \%)$, followed by Poaceae with 5 species $(6.9 \%)$, Rutaceae 4 species (5.5\%), Euphorbiaceae, cucurbitaceae, Asteraceae and Laranthaceae, 3 species (4\%) for each. However, Boraginaceae, Moraceae, Cruciferae, Simaroubaceae, Cupressaceae, Caricaceae, Ranuculaceae, Araliaceae, Rubiaceae, celastraceae, plantaginanae, Malbenaceae, Mellaceae and linaceae each have 1 species (3\%) (Table 2).

\section{Plant Parts used for medicine}

Based on the plant parts used and the method of consumption of the 91 medicinal plants identified by respondents, the 49 most commonly reported medicinal plants by the respondents in all kebeles were categorized into different groups (Figure 5). The medicinal plant parts that were commonly used were the fruit, leaf, bark, root, sap and seed. Although the leaves of all 49 of the most commonly reported species was utilized by respondents, the cluster analysis categorized these medicinal plants into three main groups and two independent species (Figure 5). The first main group comprised 19 medicinal plants that were mainly used for their leaves. However, respondents indicated that the root of Zingiber officinal, Echnops kebericho, Securidaca longepedanculata, Ziziphus abyssinica and Myrsin africana. It was 
also indicated that the bark of Ficus sur, Stereospermum kunthianum, Erythrina abyssinica, Pruns africana and Grewia ferruginea were also used by local communities. The second main group comprised 8 species that were grouped together based on the consumption of both their leaves and roots. In addition, the seeds of Lepidium sativum, Allium sativum, Ricinus communis, Coffee Arabica, Cucurpita pepo and Rhus glutinosa were also reported as potential traditional medicine. Euphorbia nubica and Rumex abyssinica, which are used for their saps and whole part, respectively, were grouped independently of the other medicinal plants (Figure 7). Likewise Mohammed Adefa [22] reported that leaves are predominated used and followed by roots in the treatment of different ailments.

Table 2: Ailment types and a number of medicinal plants used in the study area.

\begin{tabular}{|c|c|c|c|}
\hline Ailment Type & $\begin{array}{c}\text { No of } \\
\text { Medicinal } \\
\text { Plants Used }\end{array}$ & Ailment Type & $\begin{array}{c}\text { No of } \\
\text { Medicinal } \\
\text { Plants Used }\end{array}$ \\
\hline Gonorrhea & 5 & Febrile illness & 4 \\
\hline Ring worm & 5 & Constipation & 5 \\
\hline Wound & 16 & Headache & 5 \\
\hline Diarrhea & 7 & Liver disease & 2 \\
\hline Hepatitis & 7 & Tape warm & 3 \\
\hline Tooth infection & 6 & Asthma & 2 \\
\hline Swellings & 5 & Tryposis & 3 \\
\hline Tonsillitis & 4 & Breast cancer & 2 \\
\hline Evil eye & 5 & Eye infection & 3 \\
\hline Scabies & 3 & Male impotency & 2 \\
\hline Common cold & 6 & Tuberculosis & 1 \\
\hline Stomach ache & 7 & Leishmanesis & 1 \\
\hline Snake bite & 6 & Body itching & 1 \\
\hline Spider poison & 3 & Anemia & 2 \\
\hline Black leg & 3 & Typhoid & 1 \\
\hline Delivery problem & 10 & Elephantiasis & 1 \\
\hline Wart & 5 & Contraceptive & 1 \\
\hline Kidney infection & 2 & Bloody diarrhea & 2 \\
\hline Rheumatic & 2 & Cholera & 1 \\
\hline Ascribes & 2 & Over weight & 1 \\
\hline Fire burn & 2 & Bloody urine & 1 \\
\hline Worm & 4 & Ear problem & 1 \\
\hline Rabies & 3 & Bladder pain & 1 \\
\hline Amoeba & & Tick & 1 \\
\hline Evil sprite & 3 & Bleeding skin & 1 \\
\hline Anthrax & 3 & Leech & 3 \\
\hline vomiting & 4 & dandruff & 3 \\
\hline Mumps & 2 & malaria & 1 \\
\hline
\end{tabular}

In contrary, Ermias Lulekal et al. [14] have found roots have taken the highest proportion in the preparation of medicinal plants to treat diseases in Mana Angetu District. In this regards, Dawit Abebe and Ahadu Ayehu (1993), have indicated that plant harvest involving roots, rhizomes, bulb, bark and stem have a serious effects on the survival of the mother plant in it habitat. On the other hand, the results of the study showed that harvesting of roots has great impact on the plants and leads to the death of the medicinal plants. Fortunately, the plant parts which are mostly used for the preparation of the remedies in the study area were leaves and harvesting of leaves has less impact on the plant than harvesting of roots. Similar studies in Ethiopia were reported by GideyYirega [2], Mirutse Giday [11], Moa Megersa [16], Bizuneh Woldeab [18], Abiyu Eyenew [32], Tadess Birhanu [34], Nigatu Tuasha [35], Nigussie Amsalu [38], Mulugeta kebebew [39].

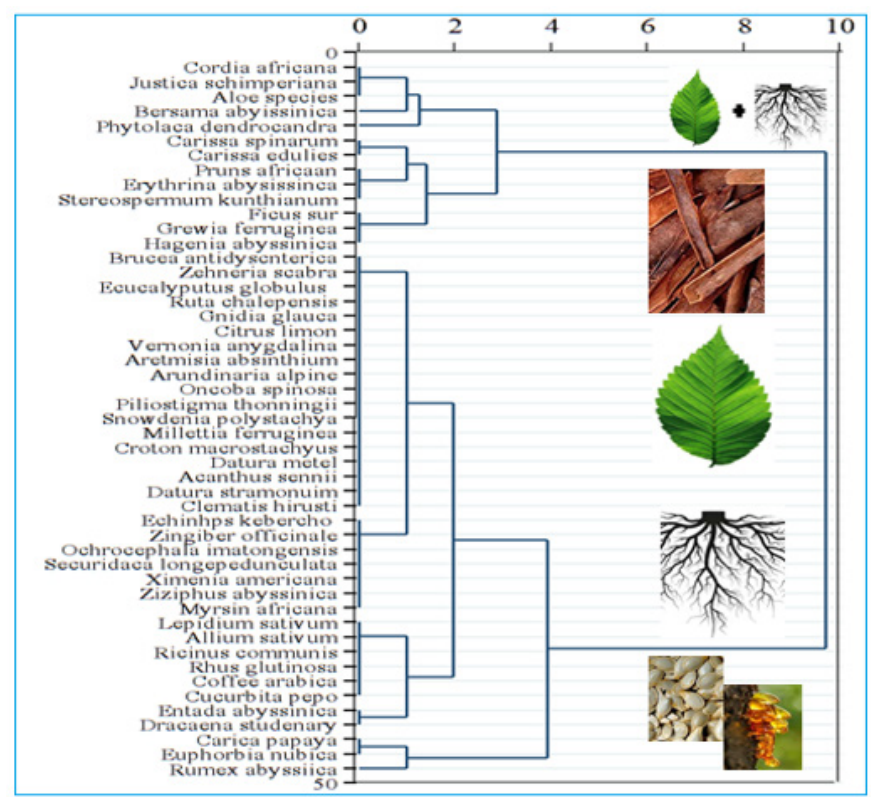

Figure 7: Dendrogram showing the classification of medicinal plant species based on the plant part used by local communities. The horizontal axis represents the distance or dissimilarity between clusters and the vertical axis represents the species and clusters (Source: own sketch).

\section{Method of preparation}

The result showed that there are various methods of preparing traditional medicines for different types of ailments. The preparations vary based on the type of disease treated and the actual site of the ailment. The principal methods of plant parts remedy preparation forms were reported to be through concoction (mixing), which accounts for $41 \%$, followed by fluid extraction (20\%), Infusion ( $8 \%$ ), Crashed \& Pounded (6.5\%), Decoction (5.5\%), Ointement (5\%), Cooked as Soup (4\%), Dryed and Powdered (3.5\%), etc. (Figure 8).

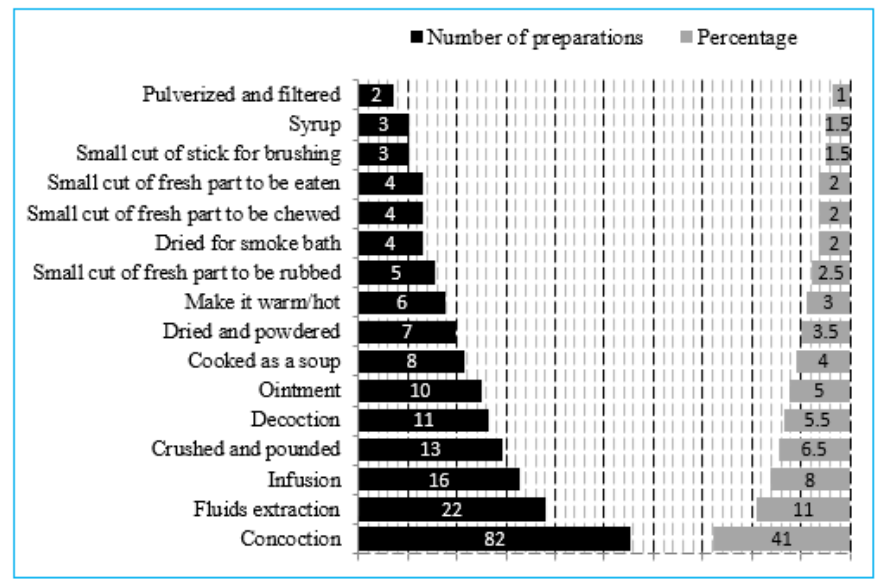

Figure 8: Preparation methods both in human and livestock ailments in the study area (Source: own sketch).

Based on the informants' information the most popular method of preparation of remedy in the study area was crushing. Similarly, various research findings mentioned crashing as the primary method of preparation in traditional plant medicine $[18,30,36]$.

\section{Route of administration}

There are various routes of administration of traditional medicinal plants by the local community. The major routes of administration in 
the study area are oral, dermal, nasal, anal, tide, ear and fumigateing. People of the study area mostly administer traditional medicine orally. Oral accounts $58.46 \%$ followed by dermal $17.69 \%$, oral and dermal $9.23 \%$ and others (Figure 9). The rout of administration may indicate the higher prevalence of internal ailments in the study area. However, the dose should be given in great care in the oral system than in the dermal since it might cause other severe internal problems.

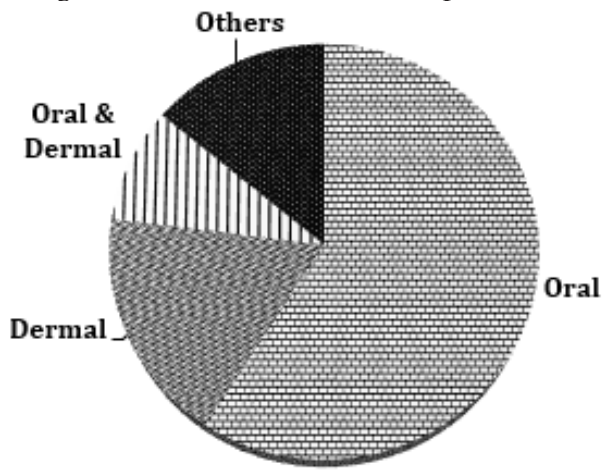

Figure 9: Route of administration both in human and livestock ailments in the study area (Source: own sketch).

Similarly, various research findings mentioned oral application as the primary route of administration in traditional plant medicines. This fact that has been documented by different authors in the other part of Ethiopia. [1,17,18,28-32,35,39].

\section{Application}

The prepared traditional medicines are applied in a number of methods. Drinking accounted for the largest 23(35.38\%), followed by smoking $11(16.76 \%)$ creaming and snafing $7(10.76 \%)$ and others (Figure 10). Internal ailments were commonly treated by making the patient drink herbal preparations; tooth infection were treated by crushing and put on the remedial plant part on the tooth surface; skin infections such as ringworm were treated by painting herbal preparations on an infected skin.

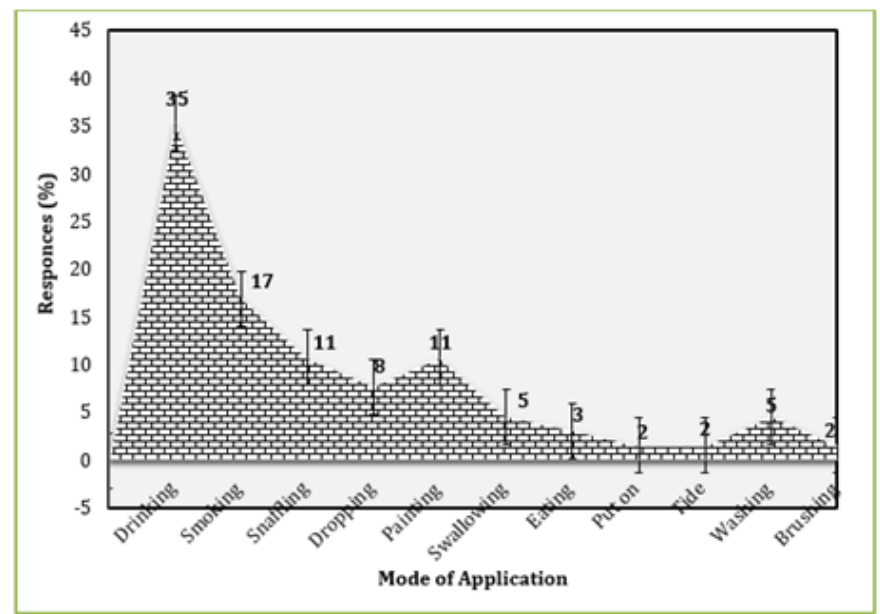

Figure 10: Ways of application of plant remedies in of both human and livestock ailment (Source: own sketch).

Some plants do have different applications procedures as per the differences in disease types. For instance, putting the leaves on tooth surface is used to cure toothache, and to tie on swollen body part is used to cure swelling. Similar results were reported elsewhere in Ethiopia by $[12,14,16,22]$

\section{Major human ailments and number of plant species used by local people}

Though more than 57 different diseases of humans were recorded as human health problem that are treated by 48 plant species (Table 2), one species can treat a single disease or a number of diseases. This shows that large numbers of diseases were treated by traditional medicine in Wombera Woreda compared to different investigations in Ethiopia. For example, Endalew Amenu (2007) reported 47 human aliments treated by 48 plant species, and Seyoum Getaneh [27] reported 78 plant species that used to treat 50 aliments of humans Getent Chekole [29] reported 135plant species that used to treat 65 aliments of humans and Nigusse Amesalu [30] reported 80 plant species that used to treat 49 aliments of humans.

According to the informants the largest number of species was used to treat snake biting, which is treated with 11 species. The next is evile eye which is treated by 9 species. Amoebae, toothache, febrile illness and wound each disease are treated by 7 species and malaria, stomach ache common cold, retained placenta and abdominal pain each disease are treated by 5 species. In addition to these, the practitioners were also visited more for diseases like gastritis, eye problem, homerriod, athlete foot and others. The local community prefers traditional healers for such diseases rather than modern medication.

Habitat, habit, plant part used, methods of preparation, rout of administration and application of human medicinal plants in the study area.

\section{Habit of human medicinal plants used to treat human}

In the study area there are many habits of medicinal plant those are herb, shrub, tree and climber. The result shows that analysis of growth forms of medicinal plants revealed that herbs constitute the largest category $19(39.58 \%)$ followed by tree $11(22.92 \%), 12(25.00 \%)$ shrub and 6(12.50\%) Climbers were recorded (Figure 11). The record of the highest number of herbaceous medicinal plant species in the study could be attributed to the fact that their presence in most parts of the study area is the bimodal rainfall and extended availability of moisture.

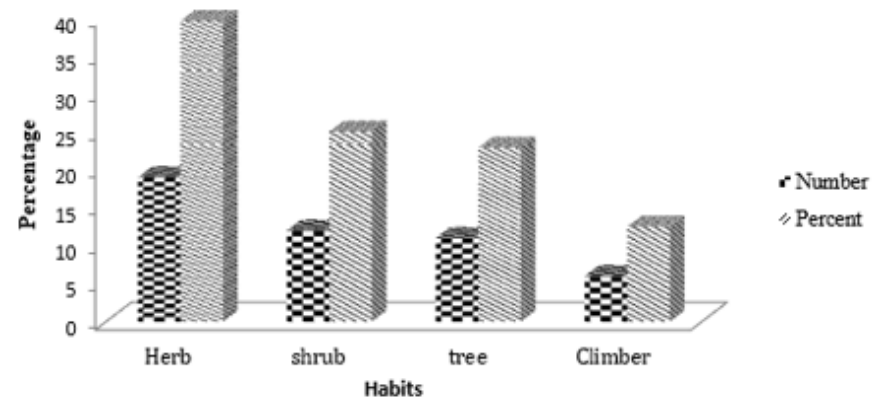

Figure 11: Habit of medicinal plants for human in the study area (Source: own sketch).

Habit distribution of medicinal plants has also been reported by some researchers $[17,18,22,24,27,28,30,31]$.

\section{Plant part used to treat human ailments}

The result of the survey showed that various parts of medicinal plants resources were employed to prepare remedies by local practitioners. From the total plant parts used for remedy preparation the leaves and the roots were the most commonly used plant parts in the preparation of remedies. The most widely used plant part for the preparations of remedy were leaves, which accounted for 10 (20.85\%) followed by roots $8(16.66 \%)$, seed $6(12.50 \%)$ bark $4(8.33 \%)$ bulb $4(8.33)$ and others (Figure 12).

The greater number of traditional remedy preparations found from leaf parts of medicinal plant species had a better accessibility during field collection, ease of preparation, and effectiveness due to bioactive components in their parts. In the same way, the detailed reason for leaves as the most potential sources of traditional remedy preparation was suggested by various studies. In my study, similar studies in other parts of Ethiopia reported and documented that leaf part are 
the most commonly used medicinal plant parts followed by root $[17,18,32,34,35,38]$ (Figure11).

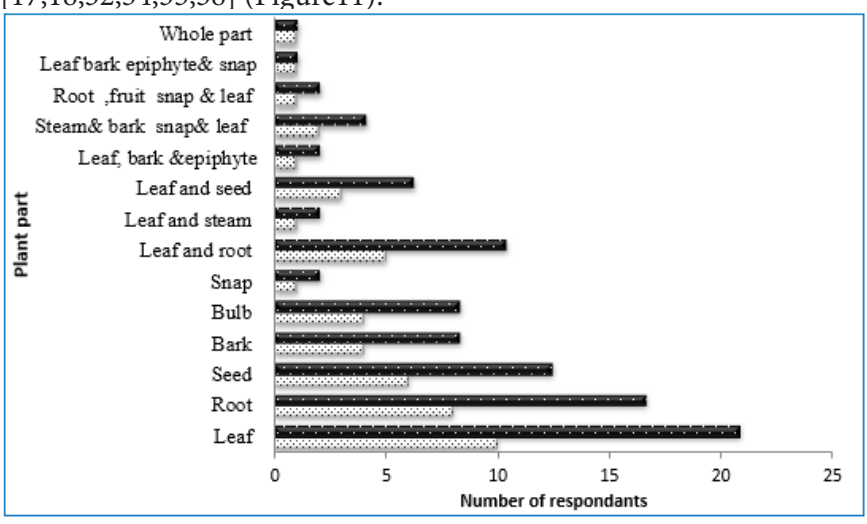

Figure 12: Percentage of medicinal plant parts used for human health treatment (Source: own sketch).

\section{Method of preparation}

The result concerning the preparation of medicine for human, the local communities employed various methods. The preparations vary based on the type of disease treated and the actual site of the ailment. The principal methods of plant parts remedy preparation forms were reported to be through concoction (mixing), which accounts for $51 \%$, followed by fluid extraction (11\%), Infusion (6\%), Crashed \& Pounded (6\%), Decoction (4\%), Ointment (3\%), Cooked as Soup (2.9\%), Dried and Powdered (2.9\%), etc. (Table 3 ).

Table 3: Method of preparation of medicinal plant used for human health treatment.

\begin{tabular}{|c|c|c|}
\hline Method of preparation & $\begin{array}{c}\text { Number of } \\
\text { preparation }\end{array}$ & Percentage \\
\hline Concoction & 71 & 50.7 \\
\hline Fluids extraction & 15 & 10.7 \\
\hline Infusion & 9 & 6.4 \\
\hline Crushed and pounded & 8 & 5.7 \\
\hline Decoction & 6 & 4.3 \\
\hline Ointment & 5 & 3.6 \\
\hline Cooked as a soup & 4 & 2.9 \\
\hline Dried and powdered & 4 & 2.9 \\
\hline Make it warm/hot & 4 & 2.9 \\
\hline Small cut of fresh part to be rubbed & 3 & 2.1 \\
\hline Dried for smoke bath & 2 & 1.4 \\
\hline Small cut of fresh part to be chewed & 2 & 1.4 \\
\hline Small cut of fresh part to be eaten & 2 & 1.4 \\
\hline Small cut of stick for brushing & 2 & 1.4 \\
\hline Syrup & 2 & 1.4 \\
\hline Pulverized and filtered & 1 & 0.7 \\
\hline
\end{tabular}

They tend to apply the mixture of different plants. The result showed that the majority of remedies were prepared from different solvents and additives which is a combination of medicinal plants. However, very few are prepared from a single plant. Similar researcher results were reported from different parts of the country by $[18,30,36]$.

\section{Route of administration}

There are various routes of administration of traditional medicinal plants prepared products by the local community. Out of 200 respondents about $129(64.5 \%)$ of them stated that the major routes of administrations were oral, dermal, fumigated and, tide. The remaining claimed to use combination routs (Figure 13).

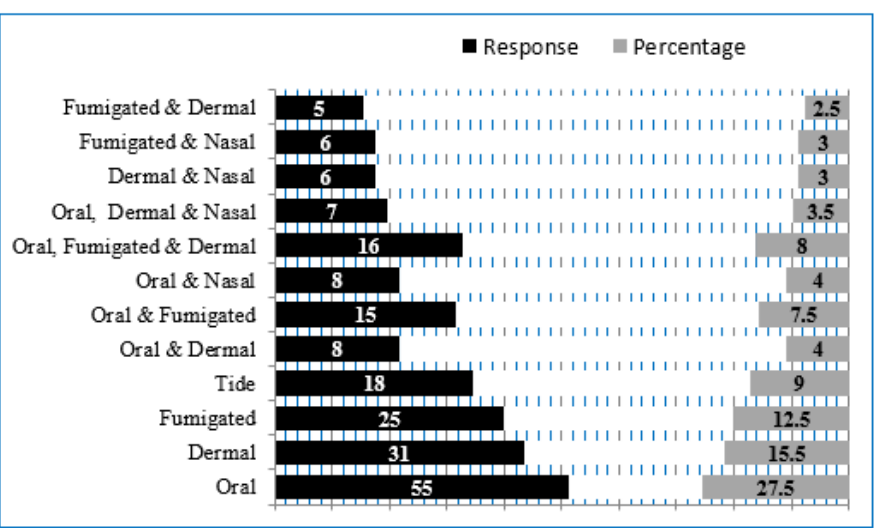

Figure 13: Route of administration of medicinal plant used for human health treatment (Source: own sketch).

Predominance of oral and dermal routes of herbal drug application in the study area could be because of high prevalence of gastro-intestinal and skin related problems in the area. Intracutaneous application of remedial preparation could also be attributed to the fact that it minimizes the chance of in toxification by drugs when it is administered orally. In addition, both oral and dermal routes permit rapid physiological reaction of prepared medicines with the pathogens and increase its curative power. In connection to this, reports showed that oral and dermal route of administration of remedies found to enhance the physiological reactions of remedies with the pathogens that in turn increase the healing power of the medication. This fact has been documented in different part of Ethiopia by $[17,18,31,32,34,35,38]$.

\section{Dosage of medicinal plants used in human ailments}

People of the study area used various units of measurement and the duration of administration to determine the dosage. Local units such as finger length (e.g., for bark, root, stem), different measuring materials (e.g. spoon, coffee cup, tea cup and glass cups) and numbers (e.g, for leaves, seeds, fruits, bulbs were used to estimate and fix the amount of medicine. But, these measurements are not accurate enough to determine the precise amount. For medicinal plants that are taken topically they do not have clear cut dosage $[5,16,32]$.

Although most of the remedies were reported to have no serious adverse effect in; in some case vomiting and temporary inflammations are occurred. These could be attributed to low toxicity of the remedies preparation of medicinal plant species used by traditional healer in the study area. However, the toxicity of some medicinal plant and the potential to do harm is a common complaint among those who would like traditional medicine to be standardized. It is commonly believed that traditional practitioner either does not known the strength of their own medicine or does not brother to fit doses to the size or the body weight of the patient (Hillendbrand, 2006). However, it was known that some traditional healers give different dosage and frequencies of application depending on age, sex, state of a person (eg. Pregnancy) and other condition. Moreover, from the interview made during the study, it was found that there was disagreement among the healers concerning the dosage system used. For example:

"Some informants suggested that two or three glass of the squeezed material from Justicia schimperiana is used to treat, snake bit, malaria, stabbing pain and toxic substance while some suggested that only one glass is enough for the same problem".

Although the measurements used to determine the dosages are not standardized and were given depending on the age, physical appearances and heath conditions; that is, children are given less dose than adults, physically strong individuals take more dose than weak individuals depending on the type of disease. Though such prescription differences were practiced in the study area; still the amount prescribed by healers for both children and adults might 
not confirm the standardized prescriptions of the modern medical literature.

The absence of any adverse effects of traditional medicines after administration were also more frequently mentioned by the traditional healers but some of the preparations were reported to have some adverse effects like diarrhea, headic, abdominal pain and vomiting. The traditional healers indicated that they use antidotes for the adverse impacts of some traditional medicines. These includes eating cooked teff flour and honey, drinking boiled coffee, doro wote, milke (ergo), suger after taking the medicine. For instance, the use of Euphorbia abisanica for the treatment of gonorrhea, the sanp is collected mixed with "teff" powdered and backed and then eaten before any food for 3 days. During that diarrhea follows, as an antidote the local healers ask the patient to drunk boiled coffee.

In addition to the use of Jatropha curcas for the treatment of rabbis, one seed are pounded, powdered, mixed with milk then the filtrate the solution is drunk. During that dihareha and vomiting follows, as an antidote the local healers ask the patient to drink "borede" a local drink and milk. In addition to the use of Niccotino tabacum for the treatment of snake bit, one leaf is pounded; powdered, mixed with water then the filtrate is drink. During that vomiting follows, as an antidote the local healers ask the patient to drank milk.

\section{Application}

The prepared traditional medicines are applied in a number of methods, drinking account the largest that account $12(25.00 \%)$, followed by smoking $10(20.83 \%)$, snffing $7(14.58 \%)$, dropping 5(10.42\%), painting $4(8.33)$ swallowing $3(6.25)$ eating $2(4.17)$ put on $1(2.08)$ tide $1(2.08)$ washing accounts $2(4.17)$ burshing $1(2.08) \%$ (Figure 14). Internal ailments were commonly treated by making the patient drink herbal preparations; tooth infection were treated by crushing and put on the remedial plant part on the tooth surface; skin infections such as ringworm were treated by painting herbal preparations on an infected skin.

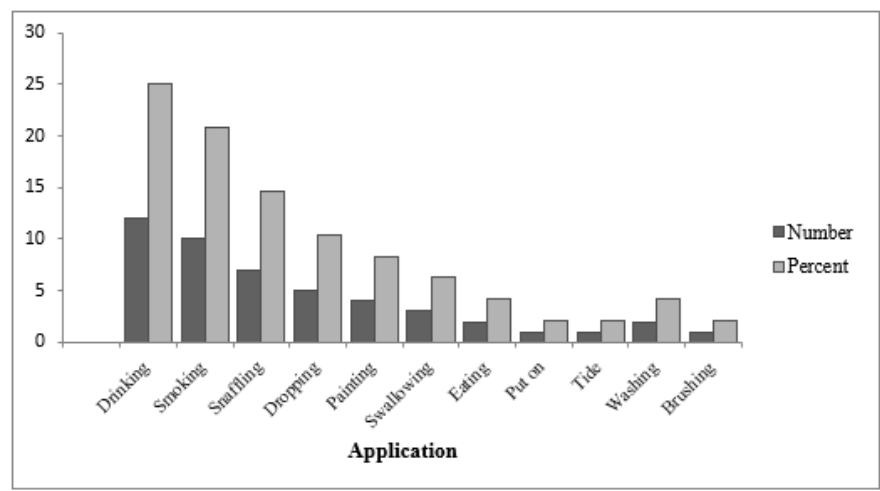

Figure 14: Application of medicinal plant used for human health treatment (Source: own sketch).

\section{Ethno medicinal plants indigenous knowledge}

Even though the first age groups of informants gave information of ethnobotanical during interview as a source of data, there was problems of giving full information like mode of preparation, dosage and plant part used as well as the local name of plants as compared to other age groups.

The use knowledge analysis showed that it is directly proportional to age increment (Figure 8). This is agreeing with that of Abiyot Berhanu [40] in which elders at higher ages reflects less medicinal plant use knowledge than adult age groups. But disagrees with Debella Hundie \& Tigist Wondemu [41] that reports medicinal plant knowledge is increased with age.

In the study area most of the informants that were found above the first group gave full information about local name, parts of plant used, mode of preparation and they reported more medicinal plants than the first age groups (Figure 15).

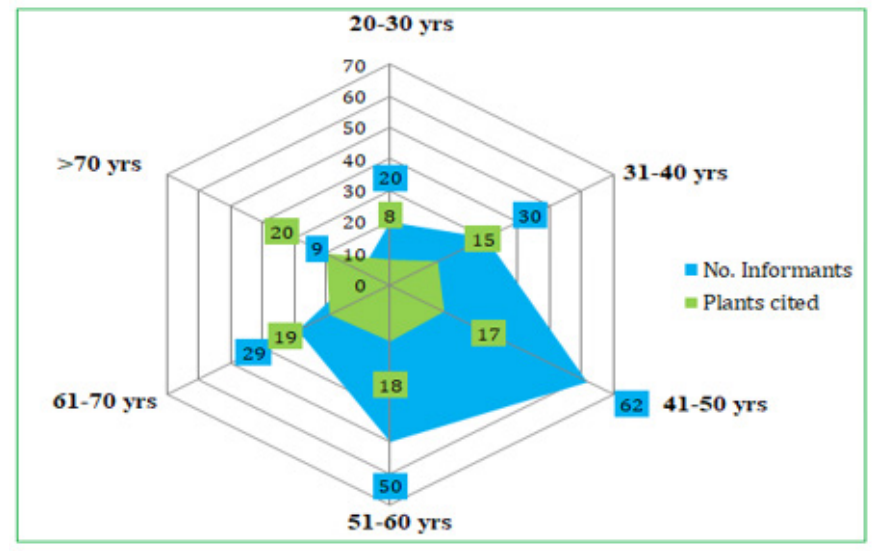

Figure 15: Radar graph which shows the relationships of Age with the knowledge of medicinal plant species use (Source: own sketch).

\section{Correlation analysis results}

The study sought to determine the relationship between the numbers of plants cited with the respondents' socio economy, and the correlation analysis results are presented in Table 4 below.

The study sought to establish correlation between the dependent variable and each of the independent variables. The dependent variable for the study was the number of plants cited as medicinal to human ailments while the independent variables are the socio economy's of the respondents such as age, sex, educational status and occupation. Correlation which is a statistical technique employed in this study to show the strength of pairs of variable is used to examine the association between the independent variables above with the dependent variable.

The correlation test was conducted at the 5\% level of significance with a 2-tailed test. Thus, the significance critical value is 0.025 above which the association is deemed to be insignificant and vice versa. The correlation analysis results obtained in the study show that all independent variables such as age, sex, educational status and occupation had a strong positive and significant correlation with the number of plants cited. Number of plants cited and Age of the respondents were strongly correlated, $r=.7 .89, p=.000$. Also, educational status and business tranumber of plants cited were moderately correlated, $r=.652, p=.000$.

\section{Regression analysis results}

The study also sought to determine the relationship between the study variables (External Factors and Internal Factors and Small scale Enterprises Transition) using regression analysis. Results are as shown below (Table 5).

The model summery revealed that the degree of association between independent and dependent variable indicated by $\mathrm{R} 0.706^{\mathrm{a}}$ which is indicating that greater relationship. $\mathrm{R}$-square value of 0.757 shows that $76 \%$ of the dependent variables are explained by the four predictor variables. From the table also, the results presented are $56 \%$ reliable as indicated by the R Square coefficient. This shows that, the study had been conducted using the representative sample (Table 6).

As illustrated in (Table 6) above, the significance value in testing the reliability of the model for the relationship between dependent variable and independent variable was obtained as 0.000 which is less than 0.05 the critical value at $95 \%$ significance level. Therefore the model is statistically significant in predicting the relationship between dependent (number of plants cited) and independent variables of the study (educational status, age, sex and occupation). The F value from the table is 82.637 indicating a significant model for the relationship as given by the regression coefficients. This shows that the overall model 
was statistically significant and reliable in explaining the influence of the predictor variables.

\section{Transferring knowledge of traditional medicinal plants}

According to the survey, knowledge transfer of medicinal plants follows vertical transfer to the most selected family member orally with great secrete. The findings of the study showed that when people gets older and older their knowledge of traditional medicine becomes better and better. Most of the informants indicated the trend of transferring knowledge is usually at old age.
The highest number informants transfer their knowledge to their elder son this accounted $56.5 \%$ followed by the elder daughter $12(12.1 \%)$, for the brother $10(10.1 \%)$ for the sister $7(7.07 \%)$ for the not to all $5(5.05$ $\%)$ for all went to known 4(4.04\%) to all the member of my family $3(3.03 \%)$ and other to fried 2(2.02\%) (Figure 16). Therefore most way of indigenous knowledge transfer in the study District was by word of mouth to a family member (especially to a son who is recognized to be an inosent and wise). Similar findings were reported for other communities in Ethiopia [30,34].

Table 4: Correlation Analysis Results.

\begin{tabular}{|c|c|c|c|c|c|c|}
\hline & & Sex & Occupation & Age & Education Status & Number of plants cited \\
\hline \multirow{3}{*}{ Sex } & Pearson Correlation & 1 & $.436^{* *}$ & $.710^{* *}$ & $.450^{* *}$ & $.520^{* *}$ \\
\hline & Sig. (2-tailed) & & 0 & 0 & 0 & 0 \\
\hline & $\mathrm{N}$ & 200 & 200 & 200 & 200 & 200 \\
\hline \multirow{3}{*}{ Occupation } & Pearson Correlation & $.436^{* *}$ & 1 & $.615^{* *}$ & $.583^{* *}$ & $.465^{* *}$ \\
\hline & Sig. (2-tailed) & 0 & & 0 & 0 & 0 \\
\hline & $\mathrm{N}$ & 200 & 200 & 200 & 200 & 200 \\
\hline \multirow{3}{*}{ Age } & Pearson Correlation & $.710^{* *}$ & $.615^{* *}$ & 1 & $.474^{* *}$ & $.789^{* *}$ \\
\hline & Sig. (2-tailed) & 0 & 0 & & 0 & 0 \\
\hline & $\mathrm{N}$ & 200 & 200 & 200 & 200 & 200 \\
\hline \multirow{3}{*}{ Education Status } & Pearson Correlation & $.450^{* *}$ & $.583^{* *}$ & $.474^{\star *}$ & 1 & $.652^{* *}$ \\
\hline & Sig. (2-tailed) & 0 & 0 & 0 & & 0 \\
\hline & $\mathrm{N}$ & 200 & 200 & 200 & 200 & 200 \\
\hline \multirow{3}{*}{ Number of plants cited } & Pearson Correlation & $.520^{* *}$ & $.465^{* *}$ & $.789^{* *}$ & $.552^{* *}$ & 1 \\
\hline & Sig. (2-tailed) & 0 & 0 & 0 & 0 & \\
\hline & $\mathrm{N}$ & 200 & 200 & 200 & 200 & 200 \\
\hline
\end{tabular}

Table 5: Regression Model Results.

\begin{tabular}{|c|c|c|c|c|c|}
\hline Model & R & R Square & Adjusted R Square & Std. Error of the Estimate & Durbin Watson \\
\hline 1 & $.706 \mathrm{a}$ & 0.757 & 0.54 & .52062 & 1.933 \\
\hline \multicolumn{7}{|c|}{ a. Predictors: (Constant), age, sex, occupation and educational status } \\
\hline
\end{tabular}

Table 6: ANOVA Results.

\begin{tabular}{|c|c|c|c|c|c|c|}
\hline Model & & Sum of Squares & df & Mean Square & F & Sig. \\
\hline \multirow{2}{*}{1} & Regression & 51513.73 & 4 & 12878.43 & 82.637 & $.000 \mathrm{~b}$ \\
\cline { 2 - 7 } & Residual & 30389.46 & 195 & 155.843 & & \\
\cline { 2 - 6 } & Total & 81903.18 & 199 & & & \\
\hline \multicolumn{7}{|c|}{ a. Dependent Variable: Number of plants cited } \\
\hline
\end{tabular}

Threatened and factor threatening medicinal plants in the study Woreda

\section{i) Threatened medicinal plant in the study area}

The citation of 20 medicinal plants based on the degree of threats was conducted using 10 key informants (Figure 17). The study results indicated that Echnops kebericho, Hygenea abyssiica and Aloe spp the most threatened medicinal plant species in the study area followed by Securidaca longepedanculata, Olea europaea, Plantago lanceolata and Croton macrostachyus and the least threatened one is Justicia shimperinata.

\section{ii) Factors threatening medicinal plants in the study area}

The cause of threats to medicinal plants can be generally grouped into natural and human induced factors. However, as reported in this study most of the causes for the threats to medicinal plants and the associated indigenous knowledge are the anthropogenic factors such as deforestation due to over exploitation of plants for different uses including charcoal making, population pressure, fire wood collection, household construction, overgrazing, cutting and burning of plants to create new agricultural expansion lands and urbanization.

Informants ranked agricultural expansion, fire wood and population pressure as the most serious threat to the medicinal plants followed by medicinal purpose and charcoal collection is lower levels of threats by the other factors (Table 7 ). Similar study by $[6,12,34,43,44]$. As expected agricultural expansion is the main cause for loss of medicinal plant because of the community in the study area depend on mixed 
agriculture as the main economic activity that haven family to support with income realized from the sale.

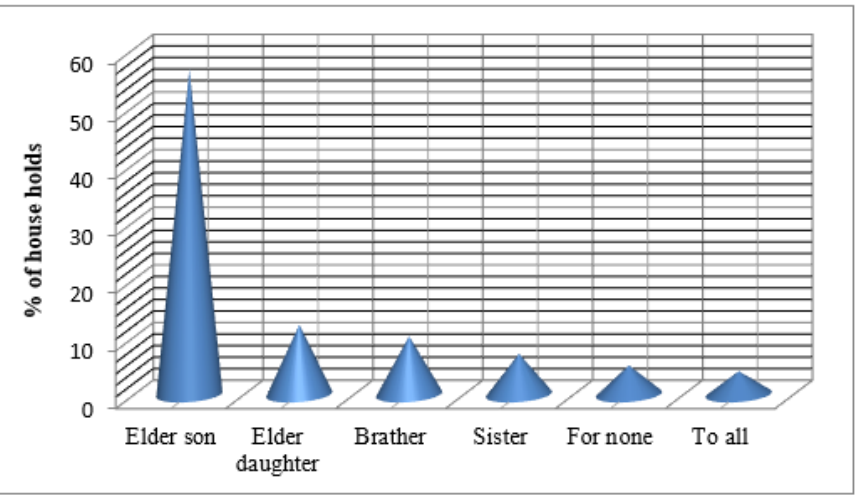

Figure 16: Transferring of knowledge of traditional medicinal plants (Source: own sketch).

This showed that, there are different threats to medicinal plants such as agricultural expansion fire wood collection and others. Furthermore, the negative impact of deforestation on medicinal plants was also reported in Mirutse Giday [37].

In this study, the information gathered from the key informants was indicated that the treats of medicinal plants increase from time to time in study area. The agricultural expansion and deforestation was the major medicinal plant treats. The finding was in line with other findings (Giday et al., 2001; Mesfin Taddes et al., 2009). This might be due to continuous agricultural expansions, deforestation and draught in addition to lack attention towards the medicinal plants. The plants are disappeared because of rapid socioeconomic, environmental and technological changes and as a result of the loss of cultural heritage under the guise of civilization (Erimias Lulekal et al., 2008) (Table 7).

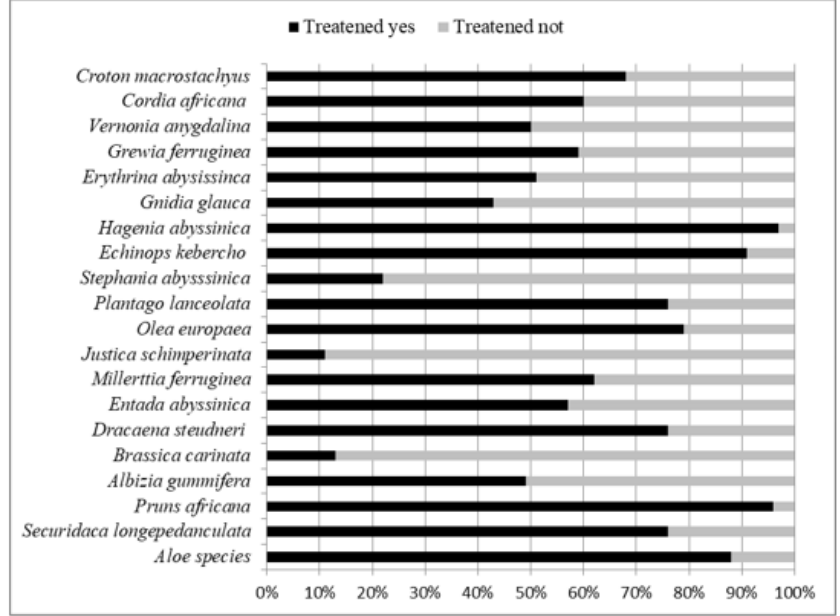

Figure 17: Status of mostly preferred wild medicinal plant species (Source: own sketch).

Table 7: Ranking of threats to medicinal plants.

\begin{tabular}{|c|c|c|c|c|c|c|c|c|c|c|c|c|}
\hline \multirow{2}{*}{ Name of plants species } & \multicolumn{12}{|c|}{ Respondents(R1-R10) } \\
\hline & $\mathrm{R}_{1}$ & $\mathrm{R}_{2}$ & $\mathrm{R}_{3}$ & $\mathrm{R}_{4}$ & $\mathrm{R}_{5}$ & $\mathrm{R}_{6}$ & $\mathrm{R}_{7}$ & $\mathrm{R}_{8}$ & $\mathrm{R}_{9}$ & $\mathrm{R}_{10}$ & Total & Rank \\
\hline Fire wood & 4 & 5 & 5 & 4 & 3 & 4 & 3 & 5 & 2 & 5 & 40 & $2^{\text {nd }}$ \\
\hline Medicinal purpose & 2 & 1 & 2 & 1 & 2 & 2 & 1 & 2 & 2 & 1 & 16 & $8^{\text {th }}$ \\
\hline Charcoal Making & 4 & 2 & 3 & 2 & 3 & 1 & 3 & 4 & 1 & 3 & 23 & $7^{\text {th }}$ \\
\hline Household tool construction & 4 & 5 & 5 & 3 & 1 & 2 & 4 & 4 & 2 & 3 & 33 & $6^{\text {th }}$ \\
\hline Over grazing & 3 & 4 & 4 & 2 & 5 & 5 & 4 & 3 & 2 & 3 & 35 & $4^{\text {th }}$ \\
\hline Agriculture expansion & 5 & 4 & 5 & 5 & 5 & 4 & 4 & 5 & 5 & 5 & 47 & $1^{\text {st }}$ \\
\hline Urbanization & 3 & 2 & 4 & 5 & 4 & 3 & 2 & 2 & 5 & 4 & 34 & $5^{\text {th }}$ \\
\hline population pressure & 5 & 2 & 3 & 4 & 5 & 5 & 3 & 3 & 4 & 5 & 39 & $3^{\text {rd }}$ \\
\hline
\end{tabular}

\section{iii) Management and conservation of medicinal plants}

At this moment natural habitats of medicinal plants in the study area are highly affected by factors mentioned above. The local people in the study area have brought only about 48 medicinal plants from wild and seventeen species from thier home garden. As a result many medicinal plants are under serious threats. So the local people should be conserve medicinal plant in-suit and ex- suit management style.

Those mines that fourty eight medicinal plants that are collected in the wild by conserve in-suit conservation method and the reaming seventeen medicinal plants that conserve by ex-suit conservation method. According to the informant information generally, there are some conservation measures that have been under taken around the world aimed at protecting threatened medicinal plant species from further destruction by create awareness for the user local people for the use and management of medicinal plant in study area.

Some authors clarify that home gardens can be refuge for wild species that are threatened in the wild by deforestation and environmental changes. Concerning this [45] reported that home gardens are being used as informal experimentation plots for new varieties and exotic species.

Medicinal plants are also left as remnants of trees, shrubs and herbs in and around agricultural fields due to their uses as forage, fuel wood, timber, and construction, spiritual and ritual needs. Protecting such multi-purpose plant species by agro-pastoralists in their localities is evidence for the existence of traditional conservation practices in the area. But this has to be strengthened to safeguard these natural resources. Of the species purposely maintained in home gardens in the country, about $6 \%$ are primarily cultivated for their medicinal values [45].

Informants also reported that the healers know time and processes of gathering and storing medicinal plants. It is once a year that some medicinal plants are collected and preserved. Lepidium sativum, Cucuribita pepo, Jatropha curcas and Ocimim basilicum seed, leaf, fruit or root are harvested, dried and preserved in roof corners or outside house, and dried parts are powdered and stored in different containers like pots, bottles or tied with clothes and used when needed.

The study indicated that many of the informants who have knowledge on traditional medicine usage give priority to the immediate use of the medicinal plants than to its sustainable future uses, as a result their harvesting style is destructive. However, some plants has protected for their spiritual and cultural purposes. Thus, these places are good sites for the protection of the medicinal plants since cutting and harvesting are not allowed in such particular areas. This was indicated that a good practice for the conservation of medicinal plants through cultivation [33,46-55]. 


\section{Conclusion}

Wombera district is one the districts in Benishangul Gumuz Regional State with abundant medicinal plant species and the associated indigenous knowledge because of its topography. In this study area 39 family, 62 genera and 91 medicinal plant species were recorded. Of these, $48(47.6 \%)$ and $17(21.9 \%)$ of the species were reported as seeing used to treat human ailments and livestock respectively, while $30.5 \%$ of them were reported to treat both livestock and human ailments. The majorities of these medicinal plant species were obtained and collected48from wild, 17 from home garden.

Analysis of growth forms of these medicinal plants that herbs constitute the largest category $24(36.9 \%)$ followed by tree $18(27.69 \%)$ shrub 16(24.61) and climber 7(10.76\%) plant species. Herbal remedies are prepared from fresh materials $45(62.23 \%)$ and dried plant materials $8(12.30 \%)$ and in both condation $18(18.46 \%)$. In the study area, 72 ailments were reported ( 57 for human and 15 for livestock) which are being treated by traditional medicinal plants of the area.

Leaves were the most frequently used plant parts followed by roots for preparation of human and livestock remedies. Most of the medicinal plants are administered orally (54.4\%) and followed dermal (7.69). The most widely used method of preparation was crashed (23.07\%), Pounding (20\%), squeezed (15.4\%), chewing (10.7\%) crushed pounded, cocking, smoking eating of the different medicinal plant parts.

The people of Wombera district are rich with indigenous knowledge in using, conserving and managing plant resources in general and medicinal plants in particular. They have a wide knowledge in using plants for various purposes such as for medicine, food, household utensils, fodder, fuel, construction, etc.

This knowledge is transferred from elders to youngsters entirely through oral traditions and personal experiences. But this way of knowledge transmission will lead to distortion of the original knowledge or total disappearance of the practice.

The major threats to medicinal plants and the associated knowledge in the study area are mainly agricultural expansion, firewood collection, population pressure, overgazering, urbanization, household tool construction, charcoal production and medicinal purpose. Therefore, use and management system awareness rising should be made among the healers so as to avoid erosion of the indigenous knowledge and to ensure its sustainable use.

\section{Acknowledgement}

We are grateful to the woreda experts, the local administration and people who supported and facilitated the field data collection. We would like to thank the Assosa Biodiversity Center for the financial and facility support. We also acknowledge gratefully the anonymous reviewer for the valuable comments on an earlier version of this article.

\section{Disclosure statement}

No potential conflict of interest was reported by the authors.

\section{References}

1. Tafesse Mesfine and Mekonnen Lemma. The role of traditional veterinary Herbal medicinal and its constraints in the animal health care system in Ethiopia. Addis Ababa Ethiopia: 2001.

2. Gidey Yirga (2010) Use of traditional medicinal plants by indigenous people in Mekele town, capital city of Tigray regional state of Ethiopia. Journal of Medicinal Plants Research 4(17): 25-50.

3. Endeshaw Bekele (2016) Study on actual situation of mechanical plants in Ethiopia prepared for Japan association for international collaboration of agriculture and forestry.
4. Farnsworth NR, Soejarto DD. Global Importance of Medicinal Plants. In: Conservation of Medicinal Plants. In: Akerel O, Hey wood N, Eds.), Cambridge University Press: UK; 1991.

5. Dawit Abebe, Ahdu Ayehu. Medicinal plants and enigmatic healthpractice of north Ethiopia, Berhanian Selam printing enterprise, Addis Ababa: 1993.

6. Ensermu Kelbessa, Sebsebe Demissew, Zerihun Woldu, Edwards. Some threatened Ethiopia. Uppsala; Sweden: 1992.

7. Yamane T. Statics, An Introduction Analysis. $2^{\text {nd }}$ Ed. New York: Harper and Row: 1967.

8. Cotton CM. Ethnobotany: Principles and Applications. John Willey and Sons LTD. UK; 1996: 424.

9. Martine G. Ethnobotany: A method of manual Chopman and Hall London UK. Grat Britain University Press Cambridge press: Ethiopia; 1995: 267.

10. Alexiades M. Collecting ethnobotanical data.An introduction to basic concepts and techniques. In: Alexiades M \& Sheldon JW, (Eds.) Selected Guideline for ethnobotanical research: A Field Manual. USA; 1996: 5894.

11. Mirutse Giday and Gobena Amene (2003). An ethnobotanical survey on plants of veterinary importance in Two Woredas of Southern Tigray. Northern Ethiopia. SINET: Ethiopian Journal Science 26: 123-136.

12. Kebu Balemie, Ensermu Kelbessa, Zemede Asfaw (2004) Indigenous medicinal plant utilization, management and threats in Fentalle area, Eastern Shewa, Ethiopia. Ethiopian Journal Biological Science 3: 37-58.

13. Haile Yineger, Dilnessaw Yewhalaw (2007) Traditional medicinal plant knowledge and use by local healers in Sekoru District, Jimma Zone, Southwestern Ethiopia. Journal of Ethnobiology and Ethnomedicine 3: 24-26.

14. Ermias Lulekal, Ensermu Kelbessa, Tamrat Bekele, Haile Yineger (2008) Plant Species Composition and Structure of The Mana Angetu Moist Montane Forest, South-Eastern Ethiopia. Journal of East African Natural History 97: 165-185.

15. Tesfaye Hailemariam, Sebsebe Demissew and Zemede Asfaw (2009) An ethnobotanical study of medicinal plants used by local people in the lowlands of Konta Special Woreda, southern nations, nationalities and peoples regional state, Ethiopia. Journal of Ethnobiology and Ethnomedicine 5: 26.

16. Moa Megersa. Ethnobotanical Study of Medicinal Plants in Wayu Tuka Wereda, East Wollega Zone of Oromia Region. Ethiopia: 2010.

17. Mulugeta Kebebew (2016) Knowledge of medicinal plants used in and around Finchảa Town, Western Ethiopia. Journal of Pharmacognosy and Phytochemistry 5(6): 110-114.

18. Bizuneh Woldeab, Reta Regassa, Tibebu Alemu, Moa Megersa (2018) Medicinal Plants Used for Treatment of Diarrhoeal Related Diseases in Ethiopia. Evid Based Complement Alternat Med 18: 4630371.

19. Dereje Mosissa, Dejene Reda (2018) The Currently Increasing Pressure on Biodiversity is Changing the Metaphysical Beliefs on Medicinal Plants Domestication: The Concern of Traditional Healers in Assosa Zone, BGRS. Western Ethiopia. American Journal of Life Science Researches 6(3): 139-158.

20. Ayeni E, Basiri B (2018) Ethnoveterinary Survey of Plants used in Treating Livestock among the Fulani people of Girei, Adamawa State, Nigeria. World News of Natural Sciences 16: 53-66.

21. Mohammed Asefa, Berhanu Abera (2010) An Ethno botanical investigation of traditional medicinal plants in Tehuledere District, South Wollo: Ethiopia; 2010: 48.

22. Bayafers Tamene (2000) A Floristic Analysis and Ethnobotanical Study of the Semi- Wet land of Cheffa Area, South Wello, Ethiopia. Agriculture and Healthcare 5: 1.

23. Debela Hunde. Use and Management of Traditional Medicinal Plants by Indigenous People of Bosat Woreda, Wolenchiti area: An ethnobotanical approach. Ethiopia; 2001. 
24. Njau AE (2001) An Ethnobotanical study of Medicinal Plants used by the Maasai People of Manayara, Arusha, Tanzania; Ethiopia.

25. Tizazu Gebre (2005) An Ethnobotanical Study of Medicinal Plants in Konso Special Woreda.

26. Mirutse Giday, Tilahun Teklehaymanot, Abebe Animut, Yalemtsehay Mekonn (2007) Medicinal plants of the Shinasha, Agew-awi and Amhara peoples in northwest Ethiopia. Journal of Ethnopharmacology 110: 516525 .

27. Seyoum Getaneh, Zerihun Girma (2014) An ethnobotanical study of medicinal plants in Deber libanos worda centreral Ethiopia. African Journal of plant science 8(7): 366-379.

28. Getnet Chokole, Zemede A, Ensermu K (2015) Ethnobotanical study of medicinal plants in the environs of Tara-gedam and Amba remnant forests of Libo Kemkem District, northwest Ethiopia. Journal of Ethnobiology and Ethnomedicine 11(4): 1-38

29. Getnet Chekol (2017) Ethnobotanical study of medicinal plants used against human ailments in Gubalafto District, Northern Ethiopia. Journa of Ethnobiology and Ethnomedicine 13: 55

30. Nigussie Amsalu, Yilkal Bezie, Mulugeta Fentahun, Addisu Alemayehu, Gashaw Amsalu (2018) Use and Conservation of Medicinal Plants by Indigenous People of Gozamin Wereda, East Gojjam Zone of Amhara Region, Ethiopia: Evidence-Based Complementary and Alternative Medicine p. 23.

31. Balcha Abera (2014) Medicinal plants used in traditional medicine by Oromo people, Ghimbi District, Southwest Ethiopia. J Ethnobiol Ethnomed 10(40): 1-15.

32. Abiyu Enyew, Zemede A, Ensermu K, Raja N (2014) Ethnobotanical Study of Traditional Medicinal Plants in and Around Fiche District, Central Ethiopia. Current Research. Journal of Biological Sciences 6(4): 154-167.

33. Meaza G, Tadesse B, Maria AS, Piero B, Gidey Y (2015) Traditional medicinal plants used by Kunama ethnic group in Northern Ethiopia. Journal of Medicinal Plants Research 9(15): 494-509.

34. Tadesse Birhanu, Dereje Abera, Eyasu Ejeta (2015) Ethnobotanical Study of Medicinal Plants in Selected HorroGudurru Woredas, Western Ethiopia. Journal of Biology, Agriculture and Healthcare 5(1): 1-12.

35. Nigatu Tuasha, Beyene Petros, Zemede Asfaw (2018) Medicinal plants used by traditional healers to treat malignancies and other human ailments in Dalle District, Sidama Zone, Ethiopia. J Ethnobiol Ethnomed $14: 15$.

36. Yihenew Simegniew Birhan, Sintayehu Leshe Kitaw, Yihalem Abebe Alemayehu, Nakachew Minuye Mengesha (2018), Ethnobotanical study of medicinal plants used to treat human diseases in Enarj Enawga District, East Gojjam Zone, Amhara Region, Ethiopia. SM J Med Plant Stud 2(1): 1006

37. Mirutse Giday. An Ethnobotanical study of Medicinal Plants Used by the People in Ethiopia. Uppsala; Sweden: 1999.

38. Nigussie Amsalu, Zemede Asfaw, Ensermu Kelbessa (2015) An ethnobotanical study of medicinal plants in Farta District, South Gondar Zone of Amhara Region. Ethiopia: 28-55.

39. Addisie Y, Yared D, Kumar PA, Tomas Z, Awol A (2012) Traditional medicinal plant used by people in Libo kemkem district, south Gondar, Ethiopia, Asian J Agric Sci 4: 171-171.
40. Abiyot Berhanu. Use and Conservation of Traditional Medicinal Plants by Indigenous People. In: Jabitehna Woreda, West Gojjam: Ethiopia: 2002.

41. Tigist Wondemu. Study of useful plants in Dodota, Sire Woreda: An Ethno botanical Approach. Addis Ababa University; Ethiopia: 2003.

42. Zerhiun W, Mesfin T (1990) The Status of the Vegetation in the Lakeregion of the Rift Valley of Ethiopia and Possibilities of its Recovery. Eth J Sci 392: $97-120$.

43. Fisseha Mesfin. An Ethnobotanical Study of Medicinal Plants in Wonago Wereda, SNNPR, Ethiopia. Addis Ababa University Addis Ababa: Ethiopia; 2009

44. Assegid Assefa, Tesfaye Abebe (2014) Ethnobotanical Study of Wild Medicinal Trees and Shrubs in Benna Tsemay District, Southern Ethiopia. Journal of Science \& Development 2(1): 17

45. Zemede Asfaw (2001) The role of home gardens in production and conservation of medicinal plants. In: Conservation and Sustainable Use of Medicinal Plants in Ethiopia. Proceeding of The National Work Shop on Biodiversity and Sustainable use of Medicinal Plants In Ethiopia.

46. Tesfaye Awas. Conservation of Medicinal Plants in Ethiopia. In: Kelbessa U, Ayale A (Eds.) The Proceedings of the First Medicinal Plant National Workshop Held in Addis Ababa. Ethiopian Health and Nutrition Research Institute: 2004, 97-107.

47. Centeral Statstical Agency (CSA). Population and Housing Census of Ethiopia, Addis Ababa, Ethiopia: 2007.

48. Fekadu Fullas. The role of indigenous medicinal plants in Ethiopia healthcare. African Foundation. Institute of Biodiversity Conservation and Research. Ethiopia: 2007.

49. Giday M, Teklehaymanot T (2013) Ethnobotanical study of plants used in management of livestock health problems by Afar people of Ada'ar District, Afar Regional State, Ethiopia. J Ethnobiol Ethnomed 9: 8.

50. Gidey Yirga, Samuel Zeraburk (2011) Ethnobotanical Study of Traditional Medicinal Plants in Gindeberet District, Western Ethiopia. Mediterranean Journal of Social Sciences 2(4).

51. Haile Yineger (2005) A study of the ethnobotany of medicinal plants and floristic composition of the dry afromontane forest at Bale Mountains National Park.

52. Haile Yineger, Ensermu Kelbessa, Tamrat Bekele, Ermias Lulekal (2008) Plants Used in Traditional Management of Human Ailments at Bale Mountain National Park, Southeastern Ethiopia. J Med Plant Res 2(6): $132-153$.

53. Medhin Zewdu, Tsige Gebre-Mariam, Kaleab Asres (2001) Global perspectives of medicinal Plants. In: Conservation and Sustainable Use of Medicinal Plants in Ethiopia, Proceeding of the National Work Shop on Biodiversity and Sustainable use of Medicinal Plants In Ethiopia; 1998: 198-203.

54. Mirgissa Kaba (1998) Utilization of plant medicine for the treatment of health problems. The case of Oromo of Chora District, Illubabor Zone, Western Ethiopia. Ethio J Health Dev 10: 161-166.

55. Teshale Sori, Merga Bekana, Girma Adugna and Ensermu Kelbessa (2004) Medicinal Plants in the Ethnoveterinary Practices of Borana Pastoralists, Southern Ethiopia. Intern J Appl Res Vet Med 2(3): 220-225. 